\title{
Analysis of Recurrent Stroke Volume between VKA (Vitamin K Antagonist) and Three NOACs (Non-Vitamin K Antagonist Oral Anticoagulants) under Oral Anticoagulant Therapy
}

\author{
Hiroaki Oguro $^{{ }^{*}}$, Ryo Mizuhara ${ }^{1}$, Satoshi Abe ${ }^{1}$, Hiroyuki Takayoshi ${ }^{1}$, Shingo Mitaki ${ }^{1}$, Keiichi Onoda ${ }^{1}$, Atsushi Nagai ${ }^{2}$ and Shuhei \\ Yamaguchi $^{1}$
}

${ }^{1}$ Department of Neurology, Shimane University, Faculty of Medicine, 1060 Nishikawatsucho, Matsue, Shimane Prefecture 690-8504, Japan ${ }^{2}$ Department of Laboratory Medicine, Shimane University, Faculty of Medicine, 1060 Nishikawatsucho, Matsue, Shimane Prefecture 690-8504, Japan

\section{Abstract}

Objective: We investigated recurrent stroke volume with nonvalvular atrial fibrillation (NVAF) patients treated with non-vitamin $\mathrm{K}$ antagonist oral anticoagulants (NOACs) about clinical backgrounds and number of recurrent stroke.

Methods: We administered three NOACs, dabigatran, rivaroxaban and apixaban in 84 post cardioembolic stroke with NVAF. In retrospective study, we measured recurrent stroke volume with MRI volumetry soft and compared them between 7 vitamin $\mathrm{K}$ anticoagulant (VKA: warfarin) cases and 10 NOACs cases under anticoagulant therapy.

Results: Of 84 cases, 27 cases were started with VKA and switched to NOACs after 7 recurrent stroke. Other 57 cases were directly started with NOACs and 10 cases with NOACs as first anticoagulants had recurrent stroke. The frequency of recurrent stroke during anticoagulant therapy are not different among VKA group and three NOACs group. Recurrent stroke volume is significantly larger in VKA group (27.4 $\mathrm{cm}^{3}$ ) than in NOACs group $\left(3.3 \mathrm{~cm}^{3}\right)$.

Conclusions: Secondary prevention with NOACs after stroke might be more beneficial by reducing recurrent infarct volume than VKA.

\section{Introduction}

Non-vitamin $\mathrm{K}$ antagonist oral anticoagulants (NOACs) have gradually changed anticoagulant therapy with non-inferiority to vascular event and decreasing major bleeding in atrial fibrillation and venous thrombosis [1-4]. We have treated post stroke patients with three types of NOACs for 4 years. However, there is no clear consensus for selection of NOACs. A meta-analysis showed that dabigatran $300 \mathrm{mg}$ daily (OR 0.66 ) and apixaban $5 \mathrm{mg}$ daily (OR 0.78 ) were more effective to prevent stroke and systemic embolism than other NOACs. It also showed that edoxaban 30mg daily (OR0.46) and apixaban $5 \mathrm{mg}$ daily (OR 0.69 ) were more effective to prevent major bleedings than other NOACs [5]. We selected 84 post stroke cases with NOACs for prevention of recurrent ischemic strokes in retrospective study. Although some studies revealed patients taking NOACs appeared to present low risk of intracranial hemorrhage and inhibit increasing of hemorrhage volume, ischemic stroke have not been fully examined [6-9]. So we examined the recurrent stroke volumes and clinical outcome under taking NOACs and compared with recurrent cases under vitamin $\mathrm{K}$ anticoagulant (VKA: warfarin).

\section{Subjects and Method}

84 post embolic stroke patients with non-valvular atrial fibrillation (NVAF) (mean age $80 \pm 9$ years) were treated with three types of NOACs for 4 years from October 2011 to September 2015. NVAF was diagnosed by atrial fibrillation within 14 days after admission without rheumatic mitral valve disease, history of prosthetic mitral valve replacement and infectios endocarditis. During the study period, the direct thrombin inhibitor, dabigatran (March 2011), the factor Xa inhibitors, rivaroxaban (April 2012) and apixaban (February 2013) were clinically available in Japan. The eligibility for anticoagulant drugs and selection of NOACs have been freely determined by each stroke neurological physician without any definite intervention. NOACs administration in cardioembolic stroke cases due to NVAF

\section{Publication History:}

Received: November 01, 2016 Accepted: December 10, 2016 Published: December 12, 2016

\section{Keywords:}

Vitamin K Antagonist, NOACs, non-valvular atrial fibrillation, Diabetes mellitus, Brain natriuretic peptide, Apixaban, Dabigatran, Rivaroxaban were divided into two arms (Figure 1). Our enrolled 84 patients with NOACs contains 15 cases with dabigatran (DA), 43 cases with rivaroxaban (RI) and 26 cases with apixaban (AP) as using NOACs finally. We divided 84 post stroke patients with three NOACs into two groups which first anticoagulant therapy with VKA or NOACs as prevention therapy of cardioembolic stroke onset.

Basic clinical characteristics included age, gender, body weight $(\mathrm{kg})$ and type of atrial fibrillation (chronic or paroxysmal). To stratify risk factors of stroke event, we calculated $\mathrm{CHADS}_{2}$ score, $\mathrm{CHA}_{2} \mathrm{DS}_{2}$-VASc score and HAS-BLED score after the onset of first cardioembolic stroke and before administration of VKA and NOACs. Hypertension was defined as blood pressure levels $\geq 140 / 90 \mathrm{mmHg}$ or by the use of antihypertensive drugs. Diabetes mellitus was defined as hemoglobin Alc (HbAlc NGSP) level $\geq 6.5 \%$ or by the use of oral antidiabetic drugs or insulin. Dyslipidemia was defined as a serum cholesterol level $\geq 220 \mathrm{mg} / \mathrm{dl}$ or by the use of lipid-lowering drugs including statin. CKD was defined as either positive proteinuria or eGFR $<60 \mathrm{ml} /$ $\mathrm{min} / 1.73 \mathrm{~m}^{2}$. The data of blood chemistry were noted with the prothrombin time-international normalized ratio (PT-INR), d-dimer, creatinine clearance and brain natriuretic peptide (BNP).The number of cases with recombinant tissue plasminogen activator (rt-PA)on acute stroke therapy was also counted retrospectively.

"Corresponding Author: Prof. Hiroaki Oguro, Department of Neurology, Shimane University Hospital, 89-1 Enya-cho, Izumo city, Shimane 693-8501, Japan; E-mail: oguro@med.shimane-u.ac.jp

Citation: Oguro H, Mizuhara R, Abe S, Takayoshi H, Mitaki S, et al. (2016) Analysis of Recurrent Stroke Volume between VKA (Vitamin K Antagonist) and Three NOACs (Non-Vitamin K Antagonist Oral Anticoagulants) under Oral Anticoagulant Therapy. Int J Pharma Sci Res 3: 116. doi: https://doi. org/10.15344/2394-1502/2016/116

Copyright: (c) 2016 Oguro et al. This is an open-access article distributed under the terms of the Creative Commons Attribution License, which permits unrestricted use, distribution, and reproduction in any medium, provided the original author and source are credited. 
Citation: Oguro H, Mizuhara R, Abe S, Takayoshi H, Mitaki S, et al. (2016) Analysis of Recurrent Stroke Volume between VKA (Vitamin K Antagonist) and Three NOACs (Non-Vitamin K Antagonist Oral Anticoagulants) under Oral Anticoagulant Therapy. Int J Pharma Sci Res 3: 116. doi: https://doi.org/10.15344/2394$1502 / 2016 / 116$

Page 2 of 6

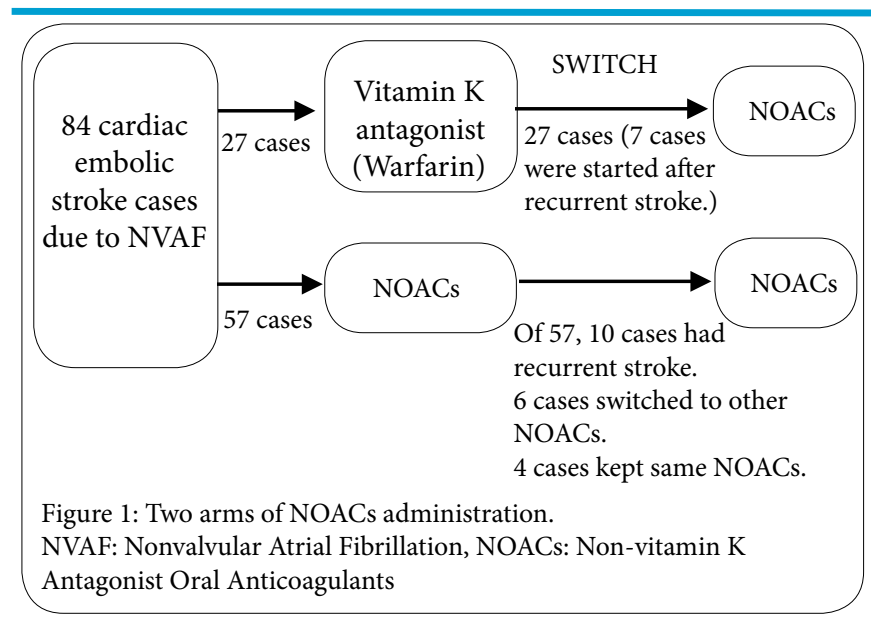

The clinical outcomes were estimated with hospitalization period (days) of first stroke event without recurrence and the period of recurrent event. It also includes improvement in National Institute of Health Stroke Scale (NIHSS) between admission and discharge during VKA and NOACs, modified Rankin Scale (mRS) on discharge, tube feeding on discharge. We calculated total stroke volume which was measured with MRI Volumetry soft: MRI cron (http://www.cabiatl. com/mricro/mricron/install.html). Total stroke volume $\left(\mathrm{cm}^{3}\right)$ is $\Sigma$ all slices of stroke lesions $\left(\mathrm{cm}^{2}\right) \times$ slice thickness $(\mathrm{cm})$ with diffusion weighted image (DWI) axial MR images with the intensity threshold used by our previous reports [10]. Modified Rankin Scale (mRS) as a clinical outcome is estimated correlation with total stroke volume. Cerebral micro bleeds and hemorrhagic infarction were diagnosed with $2^{\star}$-weighted MRI scans.

Statistical analysis: We compared clinical factors in two groups of patients with VKA or NOACs after the onset of cardioembolic stroke by Mann Whitney U test (nonparametric data). And we also compared recurrent stroke cases with VKA or NOACs, no recurrent stroke cases with VKA or NOACs and recurrent versus no recurrent stroke in each VKA and NOACs by Mann Whitney $U$ test. We used $\chi^{2}$ test between VKA group and NOACs group for evaluating several clinical factors including type of atrial fibrillation, risk factors, concurrent antiplatelet drugs, treatment by t-PA, tube feeding, and recurrent stroke during VKA or NOACs (nonparametric data). Analysis of covariance is used to assess the statistical significance of mean differences in recurrent stroke volumes and mRS between NOACs and VKA. P value of $<0.05$ was considered statistically significant.

\section{Results}

Of 84 cardiac embolic stroke cases due to NVAF, 27 cases were started with VKA and switched to NOACs after 7 recurrent stroke or without 20 recurrent event. Other 57 cases were directly started with three NOACs and 10 of 57 NOACs as first anticoagulant had recurrent stroke (Figure 1). In 27 (32\%) of 84 cases with using VKA, 7 cases had been switched into NOACs with recurrent stroke, and 20 cases had been also switched into NOACs without any event. In table 1, we showed the clinical background of VKA group and three NOACs group. The NOACs group is significantly lower in $\mathrm{CHADS}_{2}$ score, $\mathrm{CHA}_{2} \mathrm{DS}_{2}$-VASc score, HAS-BLED score, mRS on discharge and NIHSS score on admission and discharge than VKA group. VKA group is significantly higher rate of CKD with lower Ccr and higher BNP. Although recurrent stroke occurred in 7 of 27 (25.9\%) patients in VKA group and in 10 of 57 (17.5\%) in NOACs group, we could not find any difference between two groups.

\begin{tabular}{|c|c|c|c|}
\hline & VKA & NOACs & \\
\hline & $\mathrm{n}=27$ & $\mathrm{n}=57$ & $P$ value \\
\hline \multicolumn{4}{|l|}{ Basic characteristics } \\
\hline Age(y) & 81.2 & 79.5 & 0.56 \\
\hline Male gender (\%) & $15(55.5)$ & $27(47.4)$ & 0.48 \\
\hline Body weight (kg) & 53.8 & 54.3 & 0.84 \\
\hline $\begin{array}{l}\text { Type of atrial } \\
\text { fibrillation(chronic/parixismal) }\end{array}$ & $\begin{array}{l}24(88.9 \%) / \\
3(11.1 \%)\end{array}$ & $\begin{array}{l}34(59.7 \%) / \\
23(40.3 \%)\end{array}$ & 0.01 \\
\hline \multicolumn{4}{|l|}{ Risk stratification } \\
\hline $\mathrm{CHADS}_{2}$ score & 4.7 & 4 & $<0.01$ \\
\hline $\mathrm{CHA}_{2} \mathrm{DS}_{2}$-VASc score & 6.1 & 5.1 & $<0.001$ \\
\hline HAS-BLED score & 3.5 & 3.0 & 0.04 \\
\hline Hypertension (\%) & $23(85.2)$ & $50(87.7)$ & 0.74 \\
\hline Diabetes mellitus (\%) & $7(25.9)$ & $11(19.3)$ & 0.48 \\
\hline Dyslipidemia (\%) & $9(33.3)$ & $18(31.6)$ & 0.87 \\
\hline CKD (\%) & $17(63.0)$ & $12(21.1)$ & $<0.001$ \\
\hline Concurrent antiplatelet & $3(11.1)$ & $13(22.8)$ & 0.95 \\
\hline \multicolumn{4}{|l|}{ Blood chemistry } \\
\hline PT-INR on admission & 1.39 & 1.05 & $<0.0001$ \\
\hline $\mathrm{D}$-dimer $(\mu \mathrm{g} / \mathrm{ml})$ & 2.58 & 2.58 & 0.99 \\
\hline $\operatorname{Ccr}(\mathrm{mL} / \mathrm{min})$ & 52.1 & 64.5 & 0.03 \\
\hline $\mathrm{BNP}(\mathrm{pg} / \mathrm{ml})$ & 331.5 & 231.8 & 0.01 \\
\hline \multicolumn{4}{|l|}{ Treatment } \\
\hline rt-PA thrombolysis (\%) & $2(7.4)$ & $4(7.0)$ & 0.94 \\
\hline \multicolumn{4}{|l|}{ Outcomes } \\
\hline Period of hospitalization (days) & 25.8 & 21.1 & 0.44 \\
\hline NIHSS on admission & 10.3 & 7.0 & 0.01 \\
\hline NIHSS on discharge & 7.9 & 5.1 & 0.02 \\
\hline Improvement in NIHSS & -2.5 & -1.9 & 0.39 \\
\hline mRS on discharge & 3.1 & 3.0 & $<0.05$ \\
\hline Tube feeding & $9(33.3)$ & $7(12.3)$ & 0.02 \\
\hline Recurrent stroke occurred & $7(25.9)$ & $10(17.5)$ & 0.37 \\
\hline
\end{tabular}

Table 1: Clinical characteristics of the cardioembolic patients under each anticoagulant therapy with VKA or NOACs as first prevention post cardioembolic stroke.

VKA: vitamin K antagonists, warfarin, NOACs:non-vitamin K antagonist oral anticoagulants, CKD: chronic kidney disease, PT-INR: prothrombin time-international normalized ratio, rt-PA: recombinant tissue

plasminogen activator, NIHSS: National Institute of Health Stroke Scale, mRS: modified Rankin Scale

In table 2, we can recognize the baseline characteristics of recurrent or no recurrent case with each anticoagulant, VKA or NOACs. In recurrent case the VKA group had lower body weight and higher risk score with stroke event predicted by $\mathrm{CHA}_{2} \mathrm{DS}_{2}$-VASc score (similar to comparison in no recurrent) and HAS-BLED score. The VKA group in recurrent case has significantly higher rate of CKD with lower value of Ccr similar to basic characteristics in table 1. NOACs group had a shorter period of hospitalization, lower mRS on discharge and lower rate of tube feeding. On two columns right end of table 2, we can recognize that low body weight, presence of $\mathrm{CKD}$ and tube feeding is characteristic of VKA in recurrent patients. And we could find increased D-dimer in recurrent patients with NOACs $(=3.69 \mu \mathrm{g} / \mathrm{ml})$ 
Citation: Oguro H, Mizuhara R, Abe S, Takayoshi H, Mitaki S, et al. (2016) Analysis of Recurrent Stroke Volume between VKA (Vitamin K Antagonist) and Three NOACs (Non-Vitamin K Antagonist Oral Anticoagulants) under Oral Anticoagulant Therapy. Int J Pharma Sci Res 3: 116. doi: https://doi.org/10.15344/2394$1502 / 2016 / 116$

Page 3 of 6

\begin{tabular}{|c|c|c|c|c|c|c|c|c|}
\hline & \multicolumn{2}{|c|}{$\begin{array}{l}\text { Recurrent case with } \\
\text { anticoagulant }\end{array}$} & \multirow[b]{3}{*}{$P$ value } & \multicolumn{2}{|c|}{$\begin{array}{l}\text { No recurrent case with } \\
\text { anticoagulant }\end{array}$} & \multirow[b]{3}{*}{$P$ value } & \multicolumn{2}{|c|}{$\begin{array}{l}\text { Recurrent vs no } \\
\text { recurrent }\end{array}$} \\
\hline & VKA & NOACs & & VKA & NOACs & & VKA & NOACs \\
\hline & $\mathrm{n}=7$ & $\mathrm{n}=10$ & & $\mathrm{n}=20$ & $\mathrm{n}=47$ & & $\mathrm{P}$ value & $P$ value \\
\hline \multicolumn{9}{|l|}{ Basic characteristics } \\
\hline $\operatorname{Age}(y)$ & 82.4 & 78.6 & 0.41 & 80.7 & 79.8 & 0.79 & 0.43 & 0.56 \\
\hline Male gender (\%) & $3(42.9)$ & $5(50.0)$ & 0.77 & $12(60.0)$ & $22(48.8)$ & 0.32 & 0.43 & 0.85 \\
\hline Body weight (kg) & 43.4 & 58.2 & $<0.01$ & 57.4 & 53.4 & 0.23 & $<0.01$ & 0.23 \\
\hline Type of atrial fibrillation(chronic/paroxysmal) & $\begin{array}{l}7(100 \%) / \\
0(0 \%)\end{array}$ & $\begin{array}{l}8(80 \%) / \\
2(20 \%)\end{array}$ & 0.21 & $\begin{array}{l}17(85.0 \%) / \\
3(15.0 \%)\end{array}$ & $\begin{array}{l}26(55.3 \%) / \\
21(44.7 \%)\end{array}$ & $<0.05$ & 0.27 & 0.14 \\
\hline \multicolumn{9}{|l|}{ Risk stratification } \\
\hline $\mathrm{CHADS}_{2}$ score & 4.9 & 4.3 & 0.28 & 4.7 & 3.9 & $<0.05$ & 0.78 & 0.57 \\
\hline $\mathrm{CHA}_{2} \mathrm{DS}_{2}$-VASc score & 6.7 & 5.4 & 0.05 & 5.9 & 5.1 & $<0.05$ & 0.08 & 0.50 \\
\hline HAS-BLED score & 4.0 & 3.2 & $<0.05$ & 3.4 & 3.0 & 0.24 & 0.11 & 0.46 \\
\hline Hypertension (\%) & $7(100)$ & $10(100)$ & 0.99 & $16(80.0)$ & $40(85.1)$ & 0.61 & 0.19 & 0.19 \\
\hline Diabetes mellitus (\%) & $2(28.6)$ & $1(10.0)$ & 0.32 & $5(33.3)$ & $10(21.3)$ & 0.74 & 0.85 & 0.41 \\
\hline Dyslipidemia (\%) & $2(28.6)$ & $4(40.0)$ & 0.62 & $7(35.0)$ & $14(29.8)$ & 0.67 & 0.75 & 0.53 \\
\hline CKD (\%) & $7(100)$ & $2(20.0)$ & $<0.01$ & $10(50.0)$ & $10(21.3)$ & $<0.05$ & $<0.05$ & 0.92 \\
\hline Concurrent antiplatelet & $0(0)$ & $2(20.0)$ & 0.21 & $3(15.0)$ & $11(23.4)$ & 0.44 & 0.27 & 0.81 \\
\hline \multicolumn{9}{|l|}{ Blood chemistry } \\
\hline PT-INR on admission & 1.50 & 1.09 & $<0.01$ & 1.36 & 1.05 & $<0.0001$ & 0.29 & 0.19 \\
\hline D-dimer $(\mu \mathrm{g} / \mathrm{ml})$ & 1.43 & 3.69 & 0.41 & 3.09 & 2.35 & 0.42 & 0.30 & $<0.05$ \\
\hline $\operatorname{Ccr}(\mathrm{mL} / \mathrm{min})$ & 39.3 & 79.7 & $<0.01$ & 56.5 & 61.2 & 0.45 & 0.07 & 0.06 \\
\hline $\mathrm{BNP}(\mathrm{pg} / \mathrm{ml})$ & 250.4 & 235.2 & 0.20 & 362.9 & 231.0 & $<0.05$ & 0.39 & 0.91 \\
\hline \multicolumn{9}{|l|}{ Treatment } \\
\hline rt-PA thrombolysis (\%) & $0(0)$ & $0(0)$ & 0.99 & $2(10.0)$ & $4(8.5)$ & 0.84 & 0.38 & 0.34 \\
\hline \multicolumn{9}{|l|}{ Outcomes } \\
\hline Period of hospitalization (days) & 40.1 & 15.4 & $<0.05$ & 20.8 & 22.4 & 0.61 & 0.07 & 0.10 \\
\hline NIHSS on admission & 11.7 & 7.1 & 0.09 & 9.9 & 6.9 & $<0.05$ & 0.58 & 0.87 \\
\hline NIHSS on discharge & 7.8 & 3.4 & 0.05 & 7.8 & 5.4 & 0.09 & 0.69 & 0.85 \\
\hline Improvement in NIHSS & -3.8 & -3.7 & 0.99 & -2.1 & -1.6 & 0.38 & 0.74 & 0.32 \\
\hline mRS on discharge & 3.7 & 1.7 & $<0.05$ & 2.9 & 3.3 & 0.20 & 0.69 & 0.37 \\
\hline Tube feeding & $5(71.4)$ & $1(10.0)$ & $<0.01$ & $9(33.3)$ & $9(33.3)$ & 0.45 & $<0.05$ & 0.80 \\
\hline Recurrent stroke volume $\left(\mathrm{cm}^{3}\right)$ & $27.42(24.95)$ & $3.37(5.25)$ & $<0.01$ & & & & & \\
\hline
\end{tabular}

compared to recurrent patients with VKA $(=1.43 \mu \mathrm{g} / \mathrm{ml})$. The mean value of PT-INR on 7 recurrent stroke under VKA was 1.50 with under therapeutic range. Of 7 recurrent stroke under VKA, 5 patients (71\%) had been in therapeutic range less than 1.8. Of 27 VKA therapy after second prevention, only $6(22 \%)$ had been in therapeutic range more than 1.8 with PT INR.

In Table 3, 10 recurrent stroke cases (first dosage NOACs of 4 DA, 5 $\mathrm{RI}$ and $1 \mathrm{AP}$ ) under treatment of NOACs and their clinical backgrounds are presented. They have high age, low adherence, under dose of NOACs, malignancy and systemic atheromatous disease. In Table 4, recurrent stroke patients with 10 patients with NOACs and 7 patients with VKA were presented. Especially case number 10 patient in NOACs group showed small hemorrhage of left thalamus and hematoma had gradually disappeared after 20 days from stroke onset. After adjusting for age, concurrent antiplatelet, NIHSS on admission, microbleeds on MRI and complicated hemorrhage, the recurrent stroke volume is larger in VKA group $(27.4 \mathrm{~cm} 3)$ than in NOACs group $\left(3.3 \mathrm{~cm}^{3}\right)(\mathrm{p}<0.05, \mathrm{~F}=5.35)$. After adjusting for age, concurrent antiplatelet, NIHSS on admission and complicated hemorrhage, the $\mathrm{mRS}$ on discharge is lower in NOACs group (1.7) than in VKA group $(3.7)(\mathrm{p}<0.05, \mathrm{~F}=3.88)$

\section{Discussion}

Antithrombotic therapy is recommended on the basis of assessment of risk factor of cerebral infarction with NVAF. Suitable anti-coagulate drugs could be selected by both of $\mathrm{CHADS}_{2}$ scores and $\mathrm{CHA}_{2} \mathrm{DS}_{2}$-VASc 
Citation: Oguro H, Mizuhara R, Abe S, Takayoshi H, Mitaki S, et al. (2016) Analysis of Recurrent Stroke Volume between VKA (Vitamin K Antagonist) and Three NOACs (Non-Vitamin K Antagonist Oral Anticoagulants) under Oral Anticoagulant Therapy. Int J Pharma Sci Res 3: 116. doi: https://doi.org/10.15344/2394$1502 / 2016 / 116$

Page 4 of 6

\begin{tabular}{|c|c|c|c|c|c|c|c|c|c|}
\hline Case & Age & $\begin{array}{c}\text { Initial dose of } \\
\text { NOACs }\end{array}$ & $\begin{array}{l}\text { Prevention } \\
\text { type }\end{array}$ & $\begin{array}{l}\text { Interval of } \\
\text { recurrence }\end{array}$ & $\begin{array}{c}\text { Stroke } \\
\text { type }\end{array}$ & Possible reason of recurrence & $\begin{array}{c}\text { Secondary } \\
\text { dose of } \\
\text { NOACs }\end{array}$ & $\begin{array}{l}\text { BW } \\
(\mathrm{kg})\end{array}$ & $\begin{array}{c}\text { Ccr } \\
(\mathrm{ml} / \mathrm{min})\end{array}$ \\
\hline 1 & 67 & DA 300mg & 2nd & 510 & $\mathrm{CE}$ & Poor adherence & DA 300mg & 64 & 68 \\
\hline 2 & 71 & DA 220mg & 2nd & 85 & AT & Low dose & DA 300mg & 62 & 117 \\
\hline 3 & 67 & RI 15mg & 1 st & 91 & $\mathrm{CE}$ & Post CABG & DA 300mg & 66 & 103 \\
\hline 4 & 86 & RI 10mg & 2nd & 385 & $\mathrm{CE}$ & & RI 10mg & 63 & 72 \\
\hline 5 & 74 & RI 10mg & 1 st & 730 & $\mathrm{CE}$ & History of $\mathrm{CH}$ and stomach cancer & DA 220mg & 50 & 38 \\
\hline 6 & 89 & RI 10mg & 2nd & 160 & AT & & AP $5 \mathrm{mg}$ & 42 & 120 \\
\hline 7 & 72 & RI 15mg & 2nd & 160 & $\mathrm{CE}$ & & AP $10 \mathrm{mg}$ & 55 & 86 \\
\hline 8 & 80 & AP $5 \mathrm{mg}$ & 1 st & 130 & TIA & & AP $5 \mathrm{mg}$ & 75 & 62 \\
\hline 9 & 92 & DA 220mg & $2 \mathrm{nd}$ & 50 & $\mathrm{CE}$ & High age & AP $5 \mathrm{mg}$ & 56 & 53 \\
\hline 10 & 78 & DA $220 \mathrm{mg}$ & $2 \mathrm{nd}$ & 300 & $\mathrm{CH}$ & Near the old lacune & RI 10mg & 52 & 78 \\
\hline
\end{tabular}

Table 3: Stroke occurrence during NOACs.

DA: Dabigatran, RI: Rivaroxaban, AP: Apixaban,

Type of stroke:- CE: Cardioembolic Stroke, AT: Atherothrombotic Brain Infarction, TIA: Transient Ischemic Attack, CH: Cerebral Hemorrhage

\begin{tabular}{|c|c|c|c|c|c|c|c|c|c|}
\hline & Case & Age & $\begin{array}{c}\text { Initial } \\
\text { amount of } \\
\text { NOACs }\end{array}$ & $\begin{array}{l}\text { Type of } \\
\text { stroke }\end{array}$ & $\begin{array}{l}\text { Swithched } \\
\text { NOACs }\end{array}$ & $\begin{array}{c}\text { Stroke } \\
\text { volume }\left(\mathrm{cm}^{3}\right)\end{array}$ & Discharge mRS & $\begin{array}{c}\text { Micrbleeds on } \\
\text { MRI }\end{array}$ & $\begin{array}{c}\text { hemorrhagic } \\
\text { infarction }\end{array}$ \\
\hline \multirow{11}{*}{$\begin{array}{l}\text { NOACs } \\
\operatorname{group}(n=10)\end{array}$} & 1 & 67 & DA 300mg & CERe & DA 300mg & 0.48 & 1 & none & none \\
\hline & 2 & 71 & DA $220 \mathrm{mg}$ & ATRe & DA 300mg & 0.32 & 0 & none & none \\
\hline & 3 & 67 & RI 15mg & CE1st & DA 300mg & 1.16 & 2 & none & none \\
\hline & 4 & 86 & RI 10mg & CERe & RI 10mg & 15.95 & 1 & none & none \\
\hline & 5 & 74 & RI 10mg & CE1st & DA $220 \mathrm{mg}$ & 0.05 & 3 & none & none \\
\hline & 6 & 89 & RI 10mg & ATRe & API 5mg & 0.07 & 0 & none & none \\
\hline & 7 & 72 & RI $15 \mathrm{mg}$ & CERe & API $10 \mathrm{mg}$ & 1.27 & 2 & none & none \\
\hline & 8 & 80 & API $5 \mathrm{mg}$ & TIA & API $5 \mathrm{mg}$ & 0 & 0 & none & none \\
\hline & 9 & 92 & DA 220mg & CERe & API $5 \mathrm{mg}$ & 7.69 & 4 & none & none \\
\hline & 10 & 78 & DA $220 \mathrm{mg}$ & CERe & RI 10mg & 6.71 & 4 & positive & positive \\
\hline & mean & $78.6(9.1)$ & & & & $3.37(5.25)^{\star}$ & $1.7(1.5)^{*}$ & & \\
\hline \multirow{8}{*}{$\begin{array}{l}\text { VKA } \\
\operatorname{group}(n=7)\end{array}$} & 1 & 82 & & CERe & RI 10mg & 24.84 & 5 & none & none \\
\hline & 2 & 71 & & CERe & DA 300mg & 1.22 & 0 & none & none \\
\hline & 3 & 82 & & CERe & RI 10mg & 62.65 & 4 & none & none \\
\hline & 4 & 81 & & CERe & RI 10mg & 12.77 & 5 & none & none \\
\hline & 5 & 90 & & CERe & API $5 \mathrm{mg}$ & 59.09 & 4 & none & none \\
\hline & 6 & 83 & & CERe & RI $15 \mathrm{mg}$ & 3.28 & 4 & positive & positive \\
\hline & 7 & 88 & & CERe & API $5 \mathrm{mg}$ & 28.07 & 4 & none & none \\
\hline & mean & $82.4(6.1)$ & & & & $27.42(24.95)^{*}$ & $3.7(1.7)^{*}$ & & \\
\hline
\end{tabular}

Table 4: 10 recurrent stroke cases with NOACs and 7 recurrent stroke cases with VKA.

NOACs: Non-vitamin K Antagonist Oral Anticoagulants, VKA: vitamin K antagonists, warfarin, mRS: Modified Rankin Scale, DA: Dabigatran, RI:

Rivaroxaban, AP: Apixaban, Re: recurrent, 1st: First Event

Type of stroke: CE: Cardioembolic Stroke, AT: Atherothrombotic Brain Infarction, TIA: Transient Ischemic Attack, CH: Cerebral Hemorrhage ${ }^{\star}$ p $<0.05$

scores $[11,12]$. The incidence of cerebral infarction is $\geq 4 \%$ among patients with the score of $\mathrm{CHADS}_{2} \geq 2$, so all of four NOACs and VKA are recommended $[11,13]$. $\mathrm{CHA}_{2} \mathrm{DS}_{2}$-VASc score considering over 65 years of age, sex category, vascular diseases including prior myocardial infarction of $\geq 1$ is also recommended with all of four NOACs and VKA $[12,13]$. However we have no definite consensus for selection of NOACs. Our eligibility for anticoagulant drugs and selection of NOACs which had been freely determined by each physician is equal to recent multicenter prospective cohort study (da Vinci study) [14].
RE-LY trial showed that the rate of hemorrhagic stroke was $0.38 \%$ per year in the VKA group, as compared with $0.12 \%$ per year with $110 \mathrm{mg}$ of dabigatran $(\mathrm{P}<0.001)$ and $0.10 \%$ per year with $150 \mathrm{mg}$ of dabigatran $(\mathrm{P}<0.001)[1]$. ROCKET-AF trial showed that rivaroxaban group showed significant reduction in intracranial hemorrhage as compared with VKA group $(0.5 \%$ vs. $0.7 \%, \mathrm{P}=0.02)$ [4]. ARISTOTLE trial showed that the rate of major bleeding was $2.13 \%$ per year in the apixaban group, as compared with $3.09 \%$ per year in the VKA group (hazard ratio, $0.69 ; 95 \% \mathrm{CI}, 0.60$ to $0.80 ; \mathrm{P}<0.001$ )[3]. 
Citation: Oguro H, Mizuhara R, Abe S, Takayoshi H, Mitaki S, et al. (2016) Analysis of Recurrent Stroke Volume between VKA (Vitamin K Antagonist) and Three NOACs (Non-Vitamin K Antagonist Oral Anticoagulants) under Oral Anticoagulant Therapy. Int J Pharma Sci Res 3: 116. doi: https://doi.org/10.15344/2394$1502 / 2016 / 116$

Page 5 of 6

All of three NOACs have lower rate in major bleeding and intracranial hemorrhage in these major studies and superior to VKA in prevention of bleeding events. Patients with HAS-BLED score $\geq 3$ have high risk for major bleeding, so all of our three NOACs groups with mean HAS-BLED score $\geq 3$ might been adequate to use NOACs [15].

Our NOACs group is significantly lower in $\mathrm{CHADS}_{2}, \mathrm{CHA}_{2} \mathrm{DS}_{2}$ -VASc, HAS-BLED, NIHSS on admission and discharge than VKA group. And our VKA group in recurrent case has significantly higher rate of CKD with lower value of Ccr. Toyoda et al. and SAMURAI Study Investigators reported that post stroke patients taking NOACs due to NVAF had more frequently lower scores for CHADS ${ }_{2}$ CHA $\mathrm{DS}_{2}$-VASc, HAS-BLED, admission NIHSS and discharge mRS [16]. Fujimoto et al reported that NOACs were preferentially chosen for the patients with lower severity and better renal function in current status of choice of oral anticoagulants [17]. Our results equal to these reports in Japan. Our results showing the rate of stroke recurrence with $25.9 \%$ in VKA group and $17.5 \%$ in NOACs group without significant difference between two groups also equals to mega trial in ROCKET-AF and sub analysis in ARISTOTLE trial $[3,4,18]$. The reason for the characteristic of dabigatran could not be not crushed and were not fitted with a nasogastric tube in severe stroke patients with dysphagia. So our group might be tend to choice dabigatran for patients with milder neurological symptom[6,14]. Following oral administration of apixaban, urinary excretion is approximately $27 \%$ of the total clearance in healthy subjects, and it is lowest elimination in kidney among four NOACs [19-21]. Relative low renal excretion could make us choice apixaban in subjects with renal dysfunction. Exactly our patients treated with apixaban was $54.5(\mathrm{~mL} / \mathrm{min})$ in creatinine clearance and is not significantly lower than two other NOACs.

We can see several studies about stroke volume and anti-coagulant therapy. Hagii et al. reported that rivaroxaban-associated intracranial hemorrhage ( $\mathrm{ICH}$ ) had relatively small hematoma and no expansion of hematoma compared with VKA-associated ICH [7]. Matsumoto $\mathrm{M}$ et al reported that therapeutic anticoagulation by VKA (PTINR $>1.6)$ reduces infarct volume and improves neurological outcome after ischemic stroke in patients with NVAF [22]. Hakan et al reported that patients who were on therapeutic PT-INR $(>2.0)$ had smaller infarcts compared with patients without preadmission VKA use $(p<0.001)$. Preadmission VKA use associated with therapeutic level of anticoagulation can offer a benefit in limiting the extent of ischemic injury and volume in an event of acute stroke [23]. NOACs could act as neuro-protectors by inhibiting the activation of matrix metalloproteinase-9 which significantly reduces brain infarct size in early inhibition $[24,25]$. We hypothesized that NOACs might contribute stroke volume at minimum because of decreased ischemic stroke events [5]. Coagulation Factor X is an important amplifier of both the intrinsic and extrinsic activation pathways. Under-dose of VKA with sub-therapeutic PT-INR values were found in $74 \%$ of first ischemic stroke with NVAF and $68 \%$ of those with recurrent stroke $[26,27]$. Of our 7 recurrent ischemic stroke with VKA 5 patients $(71 \%)$ were under sub-therapeutic PT-INR value, and its percentage is near the previous reports. Direct Factor Xa inhibitor, rivaroxaban cause more permeable to flow in fibrin network and decreased degradation of plasma clots being formed with a looser structure in the presence of ribaroxaban [28]. The efficacy of stable blood concentration, the direct thrombin inhibitor or the factor Xa inhibitors as specific and narrow blockers in coagulating pathways with NOACs might contribute to less stroke event and smaller volume in ischemic stroke.

\section{Study Limitations}

Our study may have been influenced by relatively small sample size and retrospective study. Randomized control trial will be needed to make anticoagulant treatment definitively.

\section{Conclusion}

Secondary prevention with NOACs after stroke might be more beneficial by reducing infarct volume and modified Rankin Scale in recurrent stroke compared to VKA, warfarin.

\section{Competing Interests}

The authors declare that they have no conflict of interest in this work.

\section{Acknowledgements}

The authors have the scholarship donations from Bayer Yakuhin, Ltd. and Pfizer Japan Inc.

\section{References}

1. Connolly SJ, Ezekowitz MD, Yusuf S, Eikelboom J, Oldgren J, et al. (2009) Dabigatran versus warfarin in patients with atrial fibrillation. $\mathrm{N}$ Engl $\mathrm{J}$ Med 361: 1139-1151.

2. Giugliano RP, Ruff CT, Braunwald E, Murphy SA, Wiviott SD, et al. (2013) Edoxaban versus warfarin in patients with atrial fibrillation. $\mathrm{N}$ Engl $\mathrm{J}$ Med 369: 2093-2104.

3. Granger CB, Alexander JH, McMurray JJ, Lopes RD, Hylek EM, et al. (2011) Apixaban versus warfarin in patients with atrial fibrillation. $N$ Engl $J$ Med 365: 981-992.

4. Patel MR, Mahaffey KW, Garg J, Pan G, Singer DE, et al. (2011) Rivaroxaban versus warfarin in nonvalvular atrial fibrillation. N Engl J Med 365: 883-891.

5. Cameron C, Coyle D, Richter T, Kelly S, Gauthier K, et al. (2014) Systematic review and network meta-analysis comparing antithrombotic agents for the prevention of stroke and major bleeding in patients with atrial fibrillation. BMJ Open 4: e004301.

6. Saji N, Kimura K, Aoki J, Uemura J, Sakamoto Y (2015) Intracranial Hemorrhage Caused by Non-Vitamin K Antagonist Oral Anticoagulants (NOACs)- Multicenter Retrospective Cohort Study in Japan. Circ J 79: 1018-1023.

7. Hagii J, Tomita H, Metoki N, Saito S, Shiroto H, et al. (2014) Characteristics of intracerebral hemorrhage during rivaroxaban treatment: comparison with those during warfarin. Stroke 45: 2805-2807.

8. Hankey GJ1 (2014) Intracranial hemorrhage and novel anticoagulants for atrial fibrillation: what have we learned? Curr Cardiol Rep 16: 480.

9. Wilson D, Charidimou A, Shakeshaft C, Ambler G, White M, et al. (2016) Volume and functional outcome of intracerebral hemorrhage according to oral anticoagulant type. Neurology 86: 360-366.

10. Satou Y, Oguro H, Murakami Y, Onoda K, Mitaki S, et al. (2013) Gastroesophageal reflux during enteral feeding in stroke patients: a 24-hour esophageal pH-monitoring study. J Stroke Cerebrovasc Dis 22: 185-189.

11. Gage BF, Waterman AD, Shannon W, Boechler M, Rich MW, et al. (2001) Validation of clinical classification schemes for predicting stroke: results from the National Registry of Atrial Fibrillation. JAMA 285: 2864-2870.

12. Lip GY, Nieuwlaat R, Pisters R, Lane DA, Crijns HJ (2010) Refining clinical risk stratification for predicting stroke and thromboembolism in atrial fibrillation using a novel risk factor-based approach: the euro heart survey on atrial fibrillation. Chest 137: 263-272.

13. JCS Joint Working Group (2014) Guidelines for Pharmacotherapy of Atrial Fibrillation (JCS 2013). Circ J 78: 1997-2021.

14. Saji N, Kimura K, Tateishi Y, Fujimoto S, Kaneko N, et al. (2016) Safety and efficacy of non-vitamin $\mathrm{K}$ oral anticoagulant treatment compared with warfarin in patients with non-valvular atrial fibrillation who develop acute ischemic stroke or transient ischemic attack: a multicenter prospective cohort study (daVinci study). J Thromb Thrombolysis 42: 453-462. 
Citation: Oguro H, Mizuhara R, Abe S, Takayoshi H, Mitaki S, et al. (2016) Analysis of Recurrent Stroke Volume between VKA (Vitamin K Antagonist) and Three NOACs (Non-Vitamin K Antagonist Oral Anticoagulants) under Oral Anticoagulant Therapy. Int J Pharma Sci Res 3: 116. doi: https://doi.org/10.15344/2394$1502 / 2016 / 116$

Page 6 of 6

15. Pisters R, Lane DA, Nieuwlaat R, de Vos CB, Crijns HJ, et al. (2010) A novel user-friendly score (HAS-BLED) to assess 1-year risk of major bleeding in patients with atrial fibrillation: the Euro Heart Survey. Chest 138: 1093-1100

16. Toyoda K, Arihiro S, Todo K, Yamagami H, Kimura K, et al. (2015) Trends in oral anticoagulant choice for acute stroke patients with nonvalvular atrial fibrillation in Japan: the SAMURAI-NVAF study. Int J Stroke 10: 836-842.

17. Fujimoto Y, Kajikawa R, Izutsu N, Hirayama R, Nagashima M, et al. (2016) Choice behavior of attending physicians toward oral anticoagulants for secondary prevention of cardiogenic cerebral embolism. Jpn J Stroke 38: 239-244

18. Lopes RD, Al-Khatib SM, Wallentin L, Yang H, Ansell J, et al. (2012) Efficacy and safety of apixaban compared with warfarin according to patient risk of stroke and of bleeding in atrial fibrillation: a secondary analysis of a randomised controlled trial. Lancet 380: 1749-1758.

19. Princeton NJ (2014) Eliquis (apixaban tablets).

20. Raghavan N, Frost CE, Yu Z, He K, Zhang H, et al. (2009) Apixaban metabolism and pharmacokinetics after oral administration to humans. Drug Metab Dispos 37: 74-81.

21. Zhang D, Charles E, Frost CE, He K, Rodrigues AD, et al. (2013) Investigating the enteroenteric recirculation of apixaban, a factor $\mathrm{Xa}$ Inhibitor: Administration of activated charcoal to bile duct-cannulated rats and dogs receiving an intravenous dose and use of drug transporter knockout rats. Drug Metab Dispos 41: 906-915.

22. Matsumoto M, Okazaki S, Sakaguchi M, Ohara N, Furukado S, et al. (2011) Preadmission therapeutic anticoagulation reduces cerebral infarct volume in patients with nonvalvular atrial fibrillation. Eur Neurol 66: 277-282.

23. Ay H, Arsava EM, Gungor L, Greer D, Singhal AB, et al. (2008) Admission international normalized ratio and acute infarct volume in ischemic stroke. Ann Neurol 64: 499-506.

24. Kono S, Yamashita T, Deguchi K, Omote Y, Yunoki T, et al. (2014) Rivaroxaban and apixaban reduce hemorrhagic transformation afte thrombolysis by protection of neurovascular unit in rat. Stroke 45: 24042410.

25. Tsuji K, Aoki T, Tejima E, Arai K, Lee SR, Atochin DN, et al. (2005) Tissue plasminogen activator promotes matrix metalloproteinase- 9 upregulation after focal cerebral ischemia. Stroke 36: 1954-1959.

26. Nakamura A, Kuroda J, Ago T, Hata J, Matsuo R, et al. (2016) Causes of Ischemic Stroke in Patients with Non-Valvular Atrial Fibrillation. Cerebrovasc Dis 42: 196-204.

27. Gladstone DJ, Bui E, Fang J, Laupacis A, Lindsay MP, et al. (2009) Potentially preventable strokes in high-risk patients with atrial fibrillation who are not adequately anticoagulated. Stroke 40: 235-240.

28. Varin R, Mirshahi S, Mirshahi P, Klein C, Jamshedov J, et al. (2013) Whole blood clots are more resistant to lysis than plasma clots--greater efficacy of rivaroxaban. Thromb Res 131: e100-109. 